\title{
A mixed integer programming approach for freight railcar distribution
}

\author{
Marcello Calado ${ }^{\mathrm{a}}$, Júlio Barros ${ }^{\mathrm{a}}$, Ernesto Nobre ${ }^{\mathrm{a}}$, Bruno Prata ${ }^{\mathrm{a} *}$ \\ aUniversidade Federal do Ceará, Fortaleza, CE, Brazil \\ *baprata@ufc.br
}

\begin{abstract}
The attendance of the demand for freight transport is related to the process of allocation of the wagons that in turn is associated with the way in which the decision is taken. The distribution of wagons to the shipment terminals depends on the planning as well as on movement of the empty wagons. In addition, the trips of the empty wagons have the major financial impact on the railroad system. In such a way, an efficient mechanism of wagon distribution is vital to the railroads, because it provides important operational profits and of costs. Therefore, the purpose of this study is to analyze the problem related to the distribution of the load wagons and to develop a mathematical model that can propose an optimal scheduling of the wagons.
\end{abstract}

\section{Keywords}

Mixed integer programming. Wagons allocation. Railroad planning. Logistics.

How to cite this article: Calado, M., Barros, J., Nobre, E., \& Prata, B. (2017). A mixed integer programming approach for freight railcar distribution. Production, 27, e20152038. http://dx.doi.org/10.1590/0103-6513.203815.

\section{Introduction}

After the creation of the railways, it is observed that the level of economic development of nations is related to the density of its railway network. Nowadays, the rail passenger and freight play an important role in the economy of many countries. The railroads gave a significant expansion of the heavy freight transportation, providing rapid transport that is safe, affordable and able to overcome natural barriers.

For several years, the railways have not faced much competition in the transportation of passengers and cargo. However, in the last few decades, the railroads have lost a significative demand to other modes of transport. This fact forced the managers of railroads to seek a means to attract more customers by improving the service level and cutting costs through more efficient operations.

Generally, Brazilian railroads seem to fit into this context. Even after privatization of RFFSA - the Brazilian Federal Railway Network, the railroads has been used the same techniques of planning for the allocation of freight wagons and often this activity is done empirically. Due the lack of a computational tool for analysis and planning support, planners are faced with difficulties in the process of resource allocation. This paper aims to report the development of new formulations, based on mixed integer programming, for the problem of tactical planning regarding the allocation of freight railcars.

The remainder of this paper is organized as follows. In the next section, the planning process in freight railway transportation is presented. The third section presents a literature review for the railcar distribution problem. The fourth section presents the new formulation for the railcar distribution problem. Computational results are presented in the fifth section. In the last section, some conclusions and suggestions for future research are presented. 


\section{Planning process in freight railway transportation}

According to Alvarenga \& Novaes (2001), rail operations are characterized by high- fixed costs (expressed by equipment, terminals and railways) and low variable costs (expressed by fuel and labor). The amount of payload carried by the trains provides significant economies of scale due the practice of reduced unit cost for bulk cargo. Higher volumes tend to dilute the fixed costs per tonne, hence reducing the unit cost (Ballou, 2006).

Typically, the variable cost is related to the distance from source to the destination and accounts for 50-67\% of total costs of the service (fixed costs plus variable costs). For example, the cost of hand labor should be considered regardless of transport distance and the amount of freight transported characterizing thus portion of the fixed cost, while fuel consumption varies depending on the distance traveled. Thus, the composition of the rail total cost function of distance is obtained from the sum of the portions of the fixed cost and the variable cost.

It is observed that the distribution of assets becomes an essential factor to ensure the competitiveness and reliability of the railroad, mainly because a wagon allocated incorrectly implies higher operational costs and loss of credibility with the customer. The misallocation of a wagon appears, as a rule, to be one of the most severe types of failures of planning, especially when it involves special charges.

The planning process, specifically in the freight wagon allocation, significantly affects the economic and operational outcome of the rail industry, as it describes how the main assets will be positioned and used throughout the rail network.

In certain circumstances, it may be necessary for the railroad operation that empty wagons are moved to meet a given demand. In fact, the desire of every operator is uninterrupted handling of wagonloads, but this situation is not always possible. Each product, with its specific characteristic requires specific wagons to transport. Therefore, notwithstanding the existence of certain types of wagons in the terminal, an optimal wagon allocation may require displacement of empty wagons to meet this specification.

The wagon repositioning affects exclusively the operating expenses while it does not contribute to the company's revenues during the shuttle. The role of planning in this context is to set the number of wagons to be allocated, where they will be reallocated and when they will be available for loading, aiming the minimization of the costs involved in the decision making process.

The process of allocating the wagons is closely related to the demand for transport from the interaction between producers and consumers. The producers of goods require the shuttle for movement of raw materials, intermediate products and final product distribution. It is based on the demand, specifying the tonnage of the products being transported from a source to a destination (Crainic \& Hall, 2003).

An efficient planning to the allocation of wagons is related to minimizing the costs of displacement of wagons in response to demand for transport. Usually, the railroads form clusters through trains of wagons with various loads and with different origins and destinations, because the benefits from economies of scale. Therefore, the plan should include the right type of wagon for their transportation and their availability, as well as reconciling the flows of goods shipped. However, these flows can create frequent spatial imbalances in supply and demand for empty wagons. When this occurs, there is no alternative but to move the empty wagons from areas where there are surpluses to deficit areas in order to offset this imbalance (Joborn et al., 2004). For this reason, mathematical models capable of providing operational and economic gains by optimizing the allocation process and movement of wagons through the road network are created.

\section{Related approaches}

In recent decades, several researchers have studied the distribution of the undercarriage, in order to develop mathematical models that provide a leap in operational quality of the services offered by companies operating railroad.

Dejax \& Crainic (1987) gathered and reviewed, in a single work, management models and flow fleet of empty wagons, made suggestions and pointed research trends in this field. They also viewed the displacement of empty wagons as an exclusive problem of costs minimization, because in this situation the wagons do not generate revenue and it is for this reason that planning of the distribution of wagons is to reduce the traffic of these assets, on condition of emptiness or at least, is to seek for efficiency improvement on loaded wagon operations. Most models presented, as a premise, considered homogenous fleet and known demand. However, these authors concluded that one should develop more realistic models, addressing the transit times spent between terminals and rail interchange situations. This would imply the non-linearity of the objective functions, while in return, would induce the need to explore and develop more efficient algorithms. 
Cordeau et al. (1998) presented a literature review of the models proposed for the period of the 80s, which dealt with the distribution of empty wagons, routes and scheduling trains (both freight and passenger). The study presented an approach at all three levels of planning, with attention focused on global issues of train management. The authors consider that the repositioning of empty wagons load may contribute to the provision of a better service to customers, reducing the average waiting time for wagons, and incurring in possible reductions on the associated capital investments for equipment acquisition. In all railway undertakings, there is a great concern for the pursuit of maximizing the use of rail equipment due to of high investments associated with these features. The management of freight wagon consists of dynamically distribute the empty wagons in the mesh, in order to improve the railway's response time to the requests for wagons, and minimizing the costs associated with their shuttle.

Also in Cordeau et al. (1998), the models that deal with scheduling of trains based on departure times are discussed. The work also shown programming problems, both for the freight or passenger transport, even in slightly different ways. These authors mentioned that in the case of cargo, sometimes trains can operate without a time schedule, with departure associated with the accumulation of cargo, tonnage sufficient to form a complete train. Although this practice is still very common in North America and in Brazil, it is rarely seen in Europe, where freight trains normally operate according to scheduled times, as they do in the case of passenger transport. When the freight trains do not operate according to a schedule, are attributed probable ranges schedules associated with respective trains.

Most part of models for the optimization of wagons distribution do not take into account explicitly the economies of scale. But it is assumed, implicitly, that planning at the tactical level can confer advantages when working on a large scale. This means that the transport program is done in order to obtain the lowest cost, given the movement between each Origin-Destination.

However, most freight wagons distributions models do not usually done, explicitly, the allocation of wagons into the trains. For example, Powell \& Carvalho (1998a, b) propose a model that meets the requirements of the terminals from the definition of the number of wagons to be sent from one terminal to another, assuming that the fleet remains homogeneous over time and the demand is known. In reality, the dynamic management of fleets is explored through the adoption of a heuristic model named LQN (Logistics Queuing Network). Previously, the typical approach to the problems of fleet management formulations was through a dynamic network that used various types of arc. The study begins with a classical linear programming formulation, then, is reworked for a dynamic program. The LQN algorithm performs a linear relaxation of the formulation of dynamic programming and also makes a new derivation of gradients and algorithms for updating the control variables. Finally, the formulation replaces a single large optimization problem by a series of small problems, and the result is used to obtain the overall solution.

The transport capacity of the trains is a major concern in many railroads, therefore planning capacity utilization is undoubtedly a point of great importance. Holmberg et al. (1998) present a more detailed description of the possibilities of transport in a railway system. The main contribution of this model is related to the allocation of wagons as the capacity of the trains, according to the departure and arrival times, as well as the creation of schedules with several days in advance. However, this approach did not consider the impacts of large-scale, associated with the process consolidation/sorting in the distribution of wagons. The proposed model aims to meet the demand for transport, minimizing costs, by setting the amount of empty wagons to be moved between terminals. Considering the known supply/demand of various types of wagons, in several days time, and if demand cannot be met, it is admitted that it may be postponed to the next day.

Haghani (1989) formulates a model that combines tactical planning train makeup and distribution of empty freight cars. The flows of empty wagons are provided in tactical planning, which are considered the influences caused by the choice of the train route and makeup decisions. In this model, the rail network is represented by a time-space networks, where the nodes of this network represent the yards of the railroad at different points in time and the links consist of existing physical links as well as those links which represent yard activities. Each yard of the physical network is represented by two nodes in each period of the planning horizon. The first node, called generates the traffic departing from the yard. The second node, attracts the traffic destined to the yard. It is assumed that the model travel times between pairs of yards of the rail network are fixed. Also assume that the demand for empty wagons which is not satisfied in one time period is carried over to the next time period, without implying in a loss to the system demand.

The model proposed by Haghani (1989) has linear constraints and a nonlinear objective function. The non-linearity would increase the complexity in the solution procedure; therefore, it was avoided by assuming an overall average cost, expressed per engine over each link of the physical network. This formulation resulted in an integer linear programming model for determining the costs and delays, except for the classification, which uses convex functions of interruption. The structure of the heuristic problem induced decomposition of 
the problem into subproblems, because they can be solved more easily and then combining the solutions these problems to obtain a solution for the general problem.

Fukasawa (2002) developed two integer programming models, making use of pre-processing algorithms and decomposition to give speed boost to the process of solving global problems of planning to attend the demands and wagon flow in a railway. These problems were called Planning Assistance Problem (PAP) and Flow Wagons Problem (FWP). The PAP defines the goals of care for one day a month (tactical problem) and considers the capabilities of the rail network, the size of the fleet of wagons, blocking, classes and availability of empty wagons. For this problem, a single period model was developed, based on the model with multiple flows, with some changes to consider mounting blocks and classes of wagons. The model determines the amount of each demand for wagons to be served by defining which way each wagon and the flow of empty wagons as possible to attend. The FWP, in an operational level, determines the complete route of the railway wagons for each sequence and loading/unloading in a weekly planning horizon (several days). It is assumed that the railroad timetable and the capacity of the compositions are already defined. The goal in this case is to choose how much and how to attend every demand, with or without delay, so as to maximize the total profit.

Unlike the approach reported in this paper, the model proposed by Joborn et al. (2004) considers the allocation process, the wagons individually. This fact leads to long time to search the solution and usually requires fast heuristics to provide the resolution.

Moreover, Joborn et al. (2004) conducted studies related to operational problems in nature, which is considered the capacity of each train and cost of distributing groups of wagons to obtain economies of scale. The objective function of this model aims to determine the lowest cost related to movements OD (origin-destination) fleet of empty wagons in a given planning horizon. In this model, the possibility of using multiple trains to attend the demand for transport between an origin and destination is considered, and, if necessary, the wagons can be moved by the same train number between OD pairs. It is assumed that the supply and demand for each type of wagon and each terminal are known, and each demand can only be attended by a specific type of wagon. The formulation did not admit postponing meeting demand, however, allowing daily varying of supply, demand, the number trains and their transport capabilities. This requires the model representation in function of time.

The model proposed by Alfieri et al. (2006), instead of dealing with wagons unit, sought to determine the number of compositions needed in a simple railroad line to attend the demand of passengers. The constraints included in the model are related to maneuver trains, which differ in respect of wagons, for shorter times and occur due to the flexibility of maneuvering trains, compared to the handling of wagons unit. The model considers moreover the tactical horizon, the operational optimization problem of circulation for a determined number of trains on a set of regular lines, assuming cyclic the schedule the departure times of the trains. The goal is to seek balance among conflicting objectives of minimizing: shortage of seats (service), number of trains in operation or mileage traveled by wagons (efficiency), and the number of maneuvers (robust method). It should be noted the importance of the maneuvers for the model, as they are potential sources of disruption of traffic and avoid them it is possible to improve trains' punctuality. Finally, the approximate model is then tested on real problems through case studies on the Dutch railroad NSR - Nederlandse Spoorwegen Reizigers.

Sayarshad \& Ghoseiri (2009) present a mathematical model for optimizing the fleet sizing and allocation of wagons with the following assumptions: (i) deterministic demand, (ii) deterministic travel times, while (iii) the unmet demand is considered as a backorder. Given the complexity of the mathematical model proposed, it was not feasible the solution to large instances by exact methods. Thus, they proposed a Simulated Annealing algorithm to solve the problem.

\section{Proposed approaches: new formulations for the railcar distribution problem}

Based on the literature review, we seek to design new formulations for the problem of distribution of wagons, taking into account the practicalities of it. The input data used in the proposed models are presented below:

a) Yards/terminals and their moving abilities;

b) Wagon fleet with individual capacities of transport;

c) Travel time spent between origin-destination;

d) Program to meet demand: relationship of freight flows (origin-destination) with the total volume to be transported; wagon type adopted for transport, date of start and completion of the loading and freight carried;

e) Operating costs of the wagons;

f) Cost of the asset downtime. 
Using these data, the supply/demand of each type of wagon is estimated and their quantities determined by type of wagon adopted, planned for each day. Each movement is carefully determined in order to meet the objective function, which has 5 (five) variations depending on the alternative model being selected. They are minimizing the number of wagons retained in yards/terminals (studies show that the retention time of these wagons in the yards represents about 50\% of the total traffic) in model 1, minimizing the number of both empty and loaded wagons in model 2 , minimizing the empty wagons only in model 3 , maximizing the profit in model 4, or minimizing cost (retention/operation of wagons in the yards/terminals), respectively.

These alternatives will be analyzed in this study and will influence the mathematical formulation, which considers and defines the following parameters and decision variables, described below.

Sets:

I: Number of terminals;

$K$ : Number of type of wagons;

$P$ : Number of products to be transported;

T: Number of periods

Parameters (model input):

$k$ : defines the type of wagon allocated;

$p$ : sets the product to be transported, if the wagon is empty receives null;

$T_{\text {o(i),d(j) }}$ : determines the travel time spent by wagons that were sent by the terminal $i$ with destination $j$;

$C_{i}$ : defines the operation capability of the yard $i$ in terms of parking capacity of wagons;

$Q_{\mathrm{k}}$ : determines the carrying capacity of a given type of wagon $k$, in tonnes;

$V_{\mathrm{k}}$ : determines the fleet of a given type of wagon $k$;

$D_{\mathrm{d}}$ : featuring product demand, in tonnes, to be transported, at destination $d$;

$\mathrm{Cop}_{\mathrm{k}}$ : corresponds to the operating cost of a given type of wagon $k$;

$C S_{\mathrm{k}}$ : is the cost of maintaining a given stationary wagon type $k$;

freight $t_{\mathrm{p}}$ : matches the freight price per ton, charged for transporting a given load $p$ to a given destination;

$t_{\mathrm{i}}^{\mathrm{K}}$ : input data supplied to the model as an aid to early calculations (the first being designated period to supply this data). This is an information related to the location and number of wagons $k$, by type, in each courtyard or the railway terminal $i$.

Decision variables (model output):

$S^{K, P}{ }_{(i), d(j), t}:$ Integer variable. Sets the amount of wagons of type $k$ that leave the origin $i$ to destination $j$ at time $t$, related to the product $p$ to be transported.

$\mathrm{E}_{\mathrm{d}(\mathrm{j}), \mathrm{d}(\mathrm{i}) \mathrm{t}}^{\mathrm{k}, \mathrm{f}}$ : Integer variable. Sets the amount of wagons of type $k$ that will arrive at destination $j$, from the courtyard of origin $i$ at time $t$, noting the product $p$ being shipped.

$x_{i, t}^{k}:$ Integer variable. Represents the total number of wagons parked $k$ at the terminal $i$ in period $t$;

slack: Linear variable. It is a slack variable and corresponds to the surplus volume of cargo carried by the planning model.

As mentioned previously, the modeling found five variants in terms of the objective function, namely: Model 1, Model 2, Model 3, Model 4 and Model 5, respectively. The first variant, presented in (1a), seeks to minimize the quantity of idle wagons retained in each terminal. The function described in (1b), seeks to minimize the total number of wagons in circulation, so as to optimize the utilization of the existing fleet. While in (1c) the objective function is to minimize the total of empty wagons in circulation, noting that wagons travel in this state do not contribute directly to revenue generation. In the function (1d), the goal is to maximize profit, while in (1e) the model ponders the minimization of operational costs. Each objective function separately, was restricted in terms of equations and inequalities related to (2) to (13), in which the only exception is associated 
to the set of inequalities defined in (7a) were used to restrict each of the objective functions (1a), (1b) or (1c), while present in the Equations (7b) were used to restrict the functions (1d) or (1e).

$\min z=\sum_{i} \sum_{t} \sum_{k} x_{i, t}^{k}$

$(1-$ Model 1)

$\operatorname{minz}=\sum_{i} \sum_{j} \sum_{t} \sum_{k} \sum_{p} s_{o(i), d(t), t}^{k, p}$

(1 - Model 2)

$\operatorname{minz}=\sum_{i} \sum_{j} \sum_{t} \sum_{p} s_{o(i), d(t), t}^{e m p t y, p}$

(1 - Model 3)

$\left(\sum_{p}\right.$ slack $_{p} \cdot$ freigth $\left._{p}\right)+\sum_{j} \sum_{t} \sum_{k} \sum_{p} s_{o(i), d(t), t}^{k, p} \cdot Q_{k} \cdot$ freight $_{p}-\max z=\sum_{i}$

(1 - Model 4)

$\operatorname{minz}=\sum_{i} \sum_{j} \sum_{t} \sum_{k} \sum_{p} s_{o(i), d(t), t}^{k, p} \cdot \operatorname{Cop}_{k}+\sum_{i} \sum_{t} \sum_{k} x_{i, t}^{k} \cdot C s_{k}+\sum_{p}$ slack $_{p} \cdot 1,1 \cdot$ freigth $_{p}$

(1 - Model 5)

$x_{i, t}^{k}=x_{i, t-1}^{k}+\sum_{o(j) p} \sum_{p} E_{d(j), o(i), t}^{k, p}-\sum_{d(j) p} \sum_{o(i), d(t), t}^{k, p} \quad \forall i, t, k, p$

$s_{o(i), d(t), t}^{k, p}=E_{d(j), o(i), t+T o(i), d(j)}^{k, p} \quad \forall i, j, t, k, p$

$\sum_{d(j)} \sum_{p} s_{o(i), d(t), t}^{k, p} \leq x_{i, t-1}^{k} \quad \forall i, t, k$

$\sum_{k} x_{i, t}^{k} \leq C_{i} \quad \forall i, t$

$\sum_{i} x_{i, t}^{k} \leq V_{k} \quad \forall t, k$

$\sum_{i} \sum_{j} \sum_{t} \sum_{k} \sum_{p} s_{o(i), d(t), t}^{k, p} \cdot Q_{k} \leq D_{d} \quad \forall i, j \in D$

$\sum_{i} \sum_{j} \sum_{t} \sum_{k} \sum_{p} s_{o(i), d(t), t}^{k, p} \cdot Q_{k}+$ slack $_{p}=D_{d} \quad \forall i, j \in D$

$x_{i, t}^{k}=t_{0_{i}^{k}} \quad \forall k \in K, i \in I, t=1,2, \cdots, T$

$+\quad \forall k \in K, i \in I, t=1,2, \cdots, T x_{i, t}^{k} \in Z$

$+\quad \forall k \in K, p \in P,(i, j) \in G, t=1,2, \cdots, T s_{o(i), d(t), t}^{k, p} \in Z$

$+\quad \forall k \in K, p \in P,(i, j) \in G, t=1,2, \cdots, T E_{d(j), o(i), t}^{k, p} \in Z$

$+\quad \forall p \in$ Pslack $_{p} \in R$ 
Based on the variables shown, the set of Equations (2) provides the quantities of wagons by type $k$ remaining in the courtyard at the end of period $t$. This equation consists of three terms. The first term is the balance remaining wagons of the previous period $t-1$. The second is related to the amount of wagons designed to carry all the products that came from the terminal $i$ from the destination $j$, while the third term of the equation is turned to quantitative asset allocated ( $k$-type wagons) to carry all products that come out of the terminal $i$ to destination $j$.

The set of Equations (3), establishes the total wagon type $k$ allocated to transport product $p$ that will leave the terminal $i$ bound for destination $j$ in period $t$ must be equal to the amount of wagons of the same type and product reach the destination $j$ in period $t+T_{\text {o(i),d(j) }}$ (it is considered here $T_{\text {o(i),d(j) }}$ as the travel time spent by the respective carriages to transit between origin $i$ and destination $j$ ). The constraints defined by (4), requires that the total output of wagons type $k$ allocated to transport product $p$, destination $i$ in period $t$, with destination $j$, is limited to the availability of these assets in the courtyard $i$ in period $t-1$. This is the constraint that adopts the premise that every match will only occur at least one time after the arrival of the wagons at the destination terminal. As previously mentioned, this time is taken as time spent in terminals for operations of loading/unloading. The set of constraints (5) determines that the sum of all types of wagons contained in the terminal $i$ during the period $t$ does not exceed its capacity of that terminal. The inequalities in (6), state that the total of each type of wagons, the railway network spread (sum on $i$ ) during the period $t$, must comply with the fleet available for each type of wagon.

The set of inequalities and equations presented in (7a) and (7b) requires the model perform throughout the planning horizon, allocations that are necessary to fully meet the demand for transportation of the product $p$ from different sources $i$ and destinations $j$, leading into account the maximum capacity of each wagon type $k$. In (7b) the difference is related to the use of variable clearance to permit the use of these equations associated with the task objectives (1d) and (1e). Equation in (8), defines the initial state of the fleet of wagons on the railway, providing a picture that shows how the wagons are distributed at the initial time (first period of the planning horizon). For simplicity, it was assumed that all the wagons are parked in the courtyard $E$ are empty and available. Finally, mathematical relationships from (9) to (11) present the full set of constraints on the domain of the variable types of the proposed model. Each wagon has a maximum capacity for specific product. Already, relationship in (12) depicts the behavior of the excess cargo product $p$ with respect to the associated cost of shipping.

\section{Application of the proposed approach}

\subsection{Interface}

One of the factors that limits the use of mathematical programming models in the area of Railway Engineering is the need for professionals who are knowledgeable in the area of Operations Research (OR). In this context, one of the contributions of the approach proposed in this paper is the development of procedures which aid the use of $\mathrm{OR}$ modeling in the transportation industry by building user friendly computerized interfaces.

The input data for the proposed mathematical programming model is accomplished through an Excel spreadsheet. It becomes possible to implement a routine for using the spreadsheet for generating the inputs for the optimization model in LINGO. The Excel spreadsheet then feeds LINGO to obtain the optimal solution. After the analysis run is completed, the results are exported to Excel, enabling analysis by industry professionals with no OR experience. In the Figure 1 is presented, in a schematic form, the developed interface.

\subsection{Methodology applied in the modeling}

The mathematical model was developed from empirical data and problems experienced by the Northeastern Railway Company - CFN, which allowed us to perceive the problems in study and to define the method of solution that could best solve the problem. In the Figure 2 is illustrated the flow of cargo between different terminals of a fictitious railroad, which assisted us in preparing formulations of mixed integer linear programming.

The rail planning in order to meet demand covers the positioning and status (empty or loaded) fleet of wagons and analyzes information in possession of the best alternative to shift assets needed to transport. Clearly, the decision of the displacement is related to the cost factor, which in this case takes the input of the travel time between origin-destination (see Table 1). To simplify the process of analyzing the results, it was reported that the model for the initial time all the wagons were parked, empty and available on the destination $E$. 


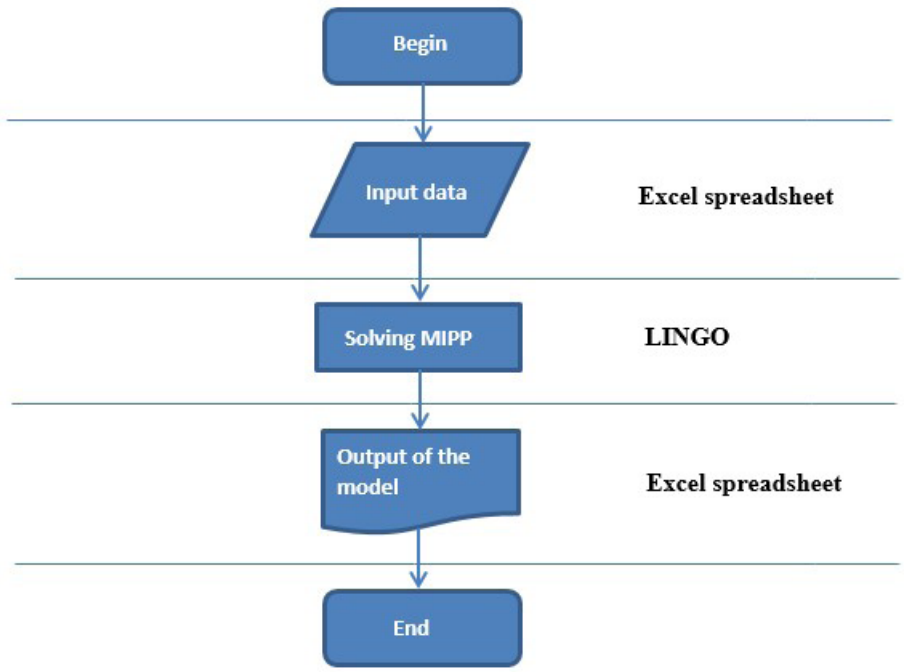

Figure 1. Flowchart of the proposed interface.

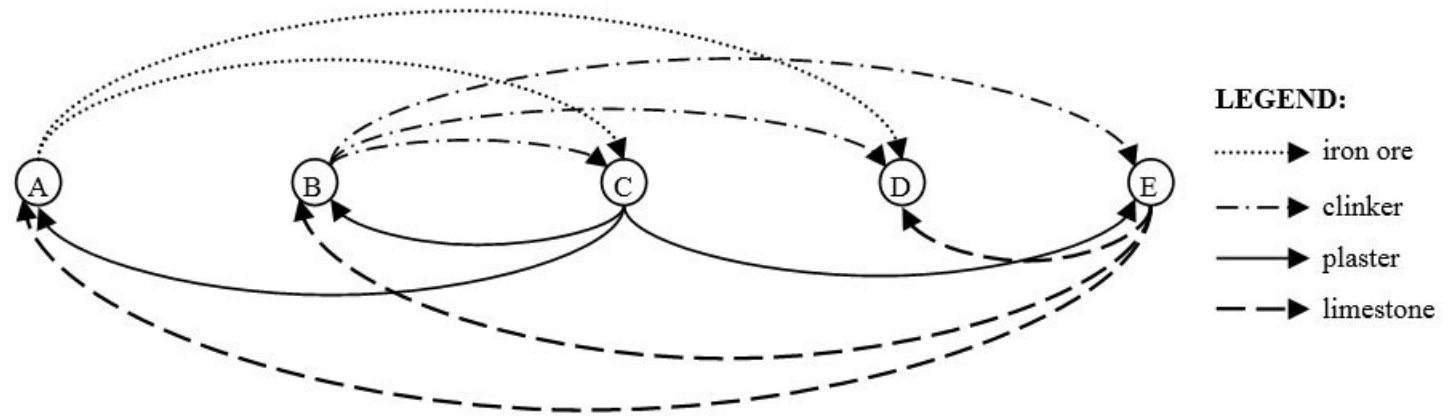

Figure 2. Simplified flow of cargo in a theoretical railroad.

Table 1. Traveling time (in days).

\begin{tabular}{cccccc}
\hline & A & B & C & D & E \\
\hline A & 0 & 1 & 2 & 3 & 4 \\
B & 1 & 0 & 1 & 2 & 3 \\
C & 2 & 1 & 0 & 1 & 2 \\
D & 3 & 2 & 1 & 0 & 1 \\
E & 4 & 3 & 2 & 1 & 0 \\
\hline
\end{tabular}

The model also considers the handling capacity of wagons in each courtyard. These operating assumptions are shown in Table 2. Moreover, it was adopted as a premise that every match will only occur in a minimum of 24 hours after arrival at the destination terminal wagons. This time was taken as time spent at the terminals of operations for loading/unloading.

The focus of this work was to study the problem of planning the allocation of freight wagons, so the methods and results presented here are specific to the undercarriage. However, it is believed that solutions can help in the development of models that solve planning problems of allocation of material traction.

Once transport demand and the types of wagons to be used are known, it is necessary that the mathematical model, described below in section 4.4, consider the transport capacity of each type of wagon and its fleet availability to undertake the necessary load flow allocations. Table 3 shows the types, capacities and fleet of wagons used in the modeling. 


\begin{tabular}{cc}
\hline Yard & \# wagons \\
\hline A & 128 \\
B & 107 \\
C & 1,322 \\
D & 810 \\
E & 932 \\
\hline
\end{tabular}

Table 3. Wagon's fleet generated by the model.

\begin{tabular}{ccc}
\hline Type & Capacity $(\mathrm{t})$ & Fleet \\
\hline Hopper & 50 & 384 \\
Gondola & 45 & 54 \\
Platform & 50 & 203 \\
Closed & 47 & 379 \\
\hline
\end{tabular}

Finally, it remains to characterize the demand of each load (in tonnes) to be moved between the origins, destinations, specifying the wagons used for personnel transport, as well as the beginning and end of the carriage. It is known that there are loads that can only be transported by a specific type of wagon (the example of bulk liquids that are carried in tank wagons), but this concern was not taken into account because it is a matter easily resolved through the data supplied to the model when setting adopted wagon for the transportation of cargo. It is worth mentioning that even though the data supplied to the model, and demands regarding freight cost are artificial and were defined from transportation programs developed by CFN, such data does not pose to be detrimental to the analysis of the proposed model.

The planning horizon under study is fifteen (15) days. This horizon was considered reasonable from the short term operational plan point of view. Table 4 presents information on the schedule of freight, provided the model for the development of the allocation of wagons that required meeting demand and its freight is charged for the service that they are observed by the objective function of economics. Besides shipping, the objective functions (1.d) and (1.e) in section 4 observe the operating costs of the wagons and the cost of downtime as presented in Table 5. It should be clarified that it was not possible to obtain the actual values of operating costs and downtime because they are considered confidential. Therefore, operating costs were defined from an estimate regarding the cargo carried, while the cost of downtime was assumed to be $10 \%$ higher than the cost of operation.

Table 4. Freight transportation scheduling adopted by the model.

\begin{tabular}{cccccccc}
\hline Product & Wagon & Origin & Destiny & Volume (t) & Freight (R\$/t) & Date(begin) & Date (end) \\
\hline lron ore & Hopper & A & C & 10,150 & 22.41 & 4 & 14 \\
Iron ore & Hopper & A & D & 9,050 & 23.71 & 6 & 11 \\
Clinker & Gondola & B & C & 800 & 47.21 & 8 & 14 \\
Clinker & Gondola & B & D & 550 & 48.14 & 5 & 12 \\
Clinker & Gondola & B & E & 1,000 & 54.06 & 12 & 13 \\
Plaster & Platform & C & A & 3,650 & 48.14 & 10 & 14 \\
Plaster & Platform & C & B & 2,900 & 46.49 & 12 & 15 \\
Plaster & Platform & C & E & 1,500 & 43.96 & 14 & 14 \\
Limestone & Closed & E & A & 7,350 & 85.34 & 9 & 12 \\
Limestone & Closed & E & B & 3,000 & 74.66 & 10 & 13 \\
Limestone & Closed & E & D & 1,250 & 59.04 & & 14 \\
\hline
\end{tabular}

Table 5. Adopted costs in the modeling.

\begin{tabular}{ccc}
\hline Type & Operational cost/t & Stoped cost/wagon \\
\hline Hopper & 23.06 & 25.37 \\
Gondola & 29.88 & 32.87 \\
Platform & 27.72 & 30.49 \\
Closed & 43.81 & 48.19 \\
\hline
\end{tabular}


In possession of the input data, the model is to calculate the supply/demand for each type of wagon and determines the quantities and types of wagons adopted for each day planned. Each movement is carefully determined so as to meet the objective function that can be: the minimization of the wagons retained in destinations/terminals (as mentioned earlier, the retention time of these wagons represents about 50\% of the total traffic); minimization of the number of trips wagons (empty and loaded, or just empty wagon); profit maximization or cost minimization (retention / operation of wagons in the yards / terminals).

\subsection{Computational results}

Aiming to evaluate the performance of the proposed formulations, the developed models were run with the input data described in the previous subsection. A summary of the formulations evaluated are shown in Table 6.

Table 6. Summary of objective functions.

\begin{tabular}{ccl}
\hline Model & Objective function & \multicolumn{1}{c}{ Description } \\
\hline Model 1 & (1a) & Minimize the quantity of idle wagons retained in each terminal \\
Model 2 & (1b) & Minimize the total number of wagons in circulation \\
Model 3 & (1c) & Minimize the total of empty wagons in circulation \\
Model 4 & (1d) & Maximize profit \\
Model 5 & (1e) & Minimize operational costs \\
\hline
\end{tabular}

The computing environment used was the solver LINGO 8.0 and Excel 2007. The LINGO was used to run the model and Excel was used to provide for data entry and to transfer the results generated by LINGO (as illustrated in Figure 1). The models were run on hardware with AMD Turion 64 X2 $1.90 \mathrm{GHz}, 2 \mathrm{~GB}$ of RAM. Next, in Table 7, are presented characteristics of the models evaluated, expressed in terms of the number of decision variables, number of decisions and computational time.

Table 7. Characteristics of the models.

\begin{tabular}{lccccc}
\hline & Model 1 & Model 2 & Model 3 & Model 4 & Model 5 \\
\hline Integer variables & 38,700 & 38,700 & 38,700 & 38,700 & 38,700 \\
Number of constraints & 1,841 & 1,841 & 1,841 & 1,841 & 1,841 \\
Computational time (s) & 7 & 4 & 4 & 5 & 5 \\
\hline
\end{tabular}

Regarding the results obtained by the five formulations evaluated, the following comments can be posted.

Throughout the planning horizon (15 days), there was on average: 231 wagons stopped without programming in Model 1, 554 wagons in Model 2, 526 wagons in Model 3, and 242 wagons both the in Model 4 and Model 5. It is worth mentioning here that in Model 2, aiming to minimize the number of wagons in circulation to meet demand, obtained the highest number of wagons retained. Already in Models 4 and 5 the quantity of wagons stopped was the same as the economic aspect considered during planning. Next, Figure 3 synthesized the number of wagons used in the charging process for each of the models.

The proposal in Figure 4 below, summarized graphically obtained planning to meet the demand for transport over the planning horizon. Allocations of wagons made at a given flow are presented at the top of this figure, where it is possible to identify the quantities of wagons coming out in each period of a given origin to a given destination. At the bottom, based on travel time expenditures the defined arrivals of wagons to their destinations are defined, as well as destinations where there stay wagons. The convention was adopted in this figure: dotted line - represents flows of empty wagons; dashed lines - shows the flows whose wagons are in the process of loading or unloading, and; continuous line - are flows of loaded wagons. As mentioned in section 4, the first period was referred to the provision of input data, therefore, no outputs/assets arrivals in this period.

Detailed planning of the allocation of boxcars obtained by objective function (1a) is shown in Figure 4 below. The care of the transport of limestone only started from the 9th period. This function manipulated 100\% of the fleet of boxcars and wagons remained empty in circulation during much of the planning horizon, being designated 251 wagons for transportation of limestone, enough to move 11,797 tons. This fact shows that there is opportunity to increase the volume of cargo programmed using the boxcar in view of 128 that were 


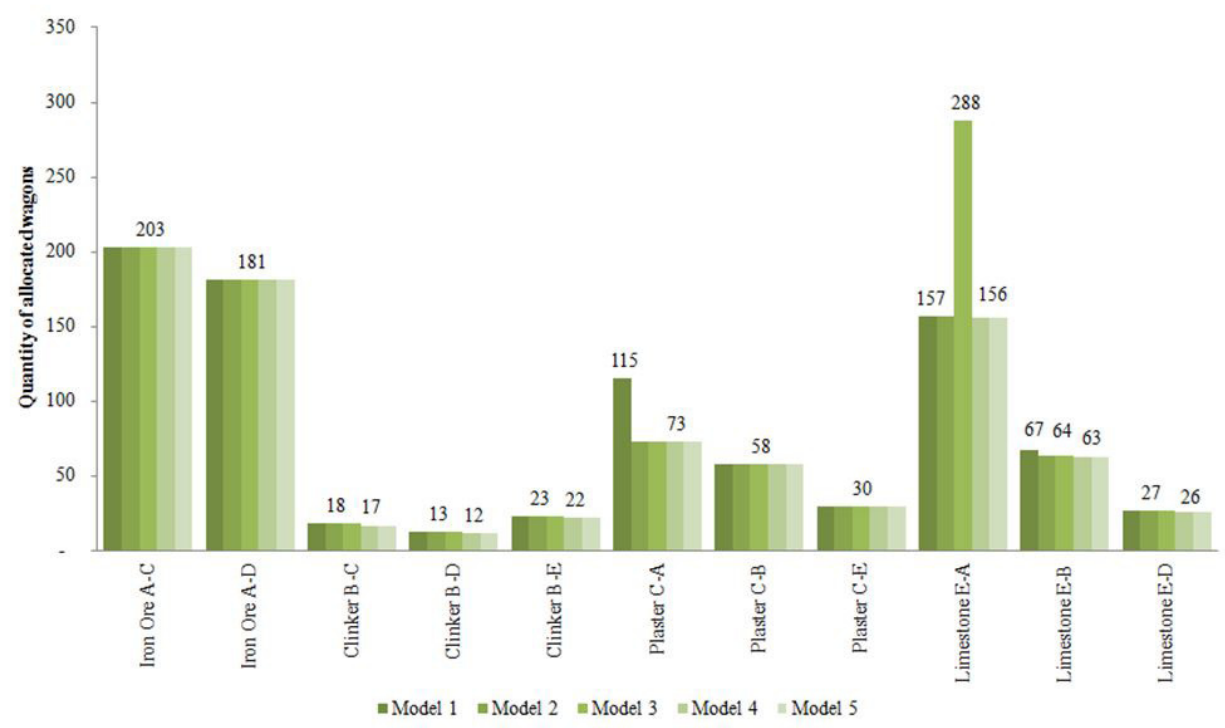

Figure 3. Quantity of wagons allocated by the models.

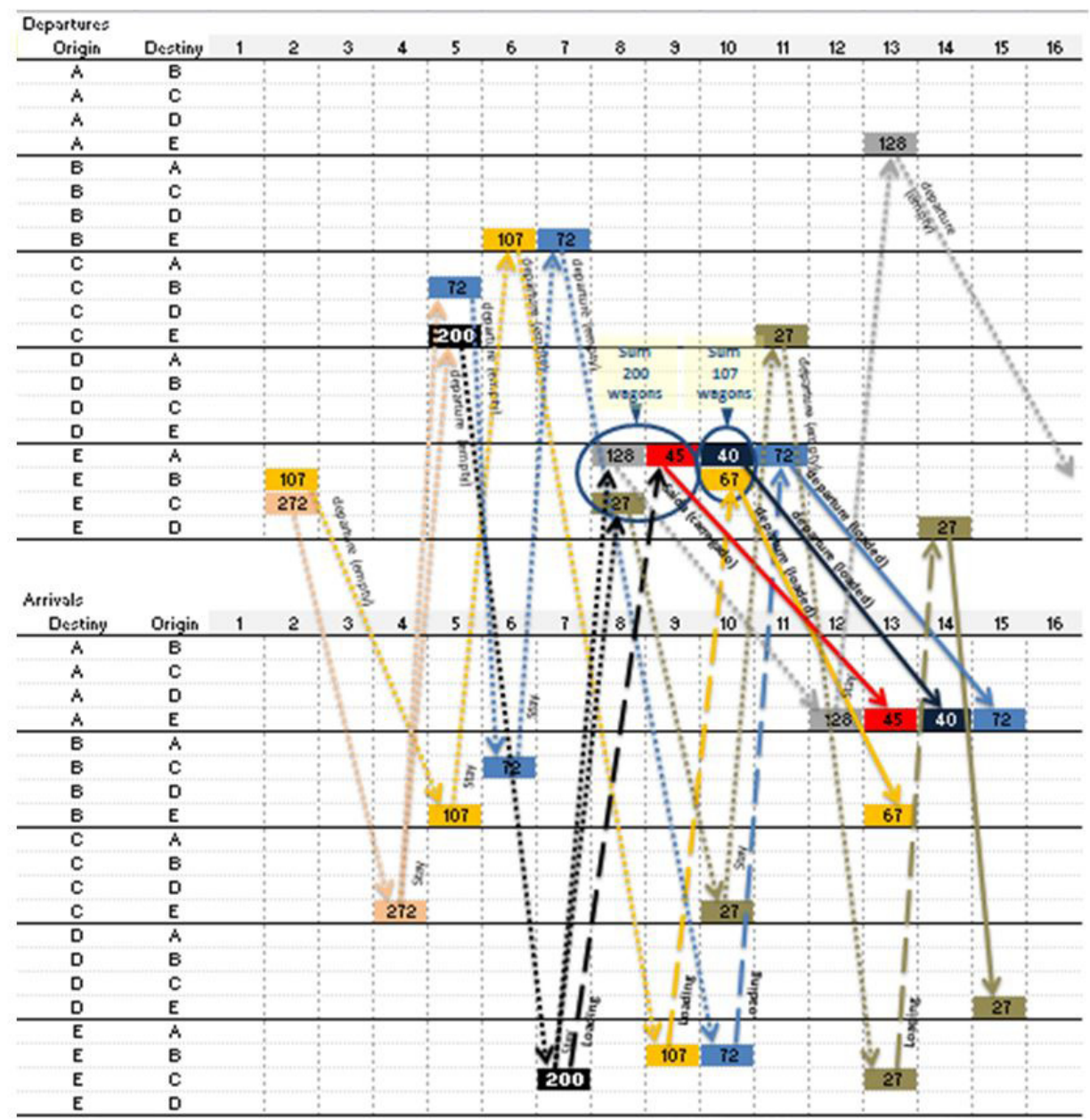

Figure 4. Solution of Model 1 - platform wagon (limestone). 
not used in active loading process. This also shows how modeling can be a useful tool during the process of planning rail, offering the analyst the opportunity to learn in detail all the limitations of the railway analyzed, it is possible to evaluate the proposition of meeting the goals of retention times in yards, commuting times, number of wagons retained for maintenance, the need for increased fleet and even if the transportation program is feasible given the existing operating assumptions.

In terms of percentage of use of availability was obtained: 77.4\% of the wagon fleet operating in Model 1 (service demand movements and movements of wagons effectively empty); 45.7\% in Model 2, 48, 5\% in the model 3; and 76.3\% in Models 4 and 5 respectively.

Tables 8 and 9 show the result of planning generated by the five models. Note that the models met the purpose for which they were designed: to meet demand through the distribution of wagons over the planning horizon. These tables bring the time needed to meet the demands studied. These times vary depending on the location of the wagons, at the initial time, compared with the deficit of these assets destinations, and in relation to the availability and capacity of rolling stock used in the transportation of the product. Evaluating the information contained in these tables, it is apparent that Model 1 was able to meet the transport of iron ore in the shortest time (9 days), whereas Models 2 and 3 led fourteen (14) days to complete charging. With regard to transport clinker, Models 1, 4 and 5 are presented the fastest. These models generate a plan so that the demand was met by the 12th day of the planning horizon, while Models 2 and 3 completed loading on day 13. But, to attend to the case of gypsum and limestone, it appears that compliance with the loading program, without exception, the five models was achieved on the fourteenth day.

Table 8. Demand meeting - Models 1, 2 and 3.

\begin{tabular}{|c|c|c|c|c|c|c|c|c|c|c|c|c|c|}
\hline \multirow{3}{*}{ Product } & \multirow{3}{*}{ Demand (t) } & \multicolumn{12}{|c|}{ Period and parcel of demand meeting } \\
\hline & & \multicolumn{4}{|c|}{ Model 1} & \multicolumn{4}{|c|}{ Model 2} & \multicolumn{4}{|c|}{ Model 3} \\
\hline & & $50 \%$ & $75 \%$ & $100 \%$ & Vol (t) & $50 \%$ & $75 \%$ & $100 \%$ & Vol (t) & $50 \%$ & $75 \%$ & $100 \%$ & Vol (t) \\
\hline lron ore & 19,200 & $7^{\text {th }}$ & $8^{\text {th }}$ & $9^{\text {th }}$ & 19,200 & $10^{\text {th }}$ & $11^{\text {th }}$ & $14^{\text {th }}$ & 19,200 & $11^{\text {th }}$ & $14^{\text {th }}$ & $14^{\text {th }}$ & 19,200 \\
\hline Clinker & 2,350 & $8^{\text {th }}$ & $12^{\text {th }}$ & $12^{\text {th }}$ & 2,430 & $8^{\text {th }}$ & $13^{\text {th }}$ & $13^{\text {th }}$ & 2,430 & $8^{\text {th }}$ & $13^{\text {th }}$ & $13^{\text {th }}$ & 2,430 \\
\hline Plaster & 8,050 & $11^{\text {th }}$ & $11^{\text {th }}$ & $14^{\text {th }}$ & 10,150 & $13^{\text {th }}$ & $13^{\text {th }}$ & $14^{\text {th }}$ & 8,050 & $13^{\text {th }}$ & $13^{\text {th }}$ & $14^{\text {th }}$ & 8,050 \\
\hline Limestone & 11,600 & $10^{\text {th }}$ & $11^{\text {th }}$ & $14^{\text {th }}$ & 11,797 & $9^{\text {th }}$ & $10^{\text {th }}$ & $14^{\text {th }}$ & 11,656 & $9^{\text {th }}$ & $9^{\text {th }}$ & $14^{\text {th }}$ & 17,813 \\
\hline
\end{tabular}

Table 9. Demand meeting - Models 4 and 5.

\begin{tabular}{|c|c|c|c|c|c|c|c|c|c|}
\hline \multirow{3}{*}{ Product } & \multirow{3}{*}{ Demand (t) } & \multicolumn{8}{|c|}{ Period and parcel of demand meeting } \\
\hline & & \multicolumn{4}{|c|}{ Model 4} & \multicolumn{4}{|c|}{ Model 5} \\
\hline & & $50 \%$ & $75 \%$ & $100 \%$ & Vol (t) & $50 \%$ & $75 \%$ & $100 \%$ & Vol (t) \\
\hline Iron ore & 19,200 & $8^{\text {th }}$ & $10^{\text {th }}$ & $10^{\text {th }}$ & 19,200 & $8^{\text {th }}$ & $10^{\text {th }}$ & $10^{\text {th }}$ & 19,200 \\
\hline Clinker & 2,350 & $8^{\text {th }}$ & $12^{\text {th }}$ & $12^{\text {th }}$ & 2,295 & $8^{\text {th }}$ & $12^{\text {th }}$ & $12^{\text {th }}$ & 2,295 \\
\hline Plaster & 8,050 & $11^{\text {th }}$ & $12^{\text {th }}$ & $14^{\text {th }}$ & 8,050 & $11^{\text {th }}$ & $12^{\text {th }}$ & $14^{\text {th }}$ & 8,050 \\
\hline Limestone & 11,600 & $9^{\text {th }}$ & $10^{\text {th }}$ & $14^{\text {th }}$ & 11,515 & $10^{\text {th }}$ & $11^{\text {th }}$ & $14^{\text {th }}$ & 11,656 \\
\hline
\end{tabular}

\section{Conclusions}

The proposed models considered operational issues such as travel time, stay in the courtyard; fleet, capacity and types of wagons adopted; ability of yards and operating costs, but one has to admit that to include all details would be an extremely difficult task due to the complexity related to control, planning and operation of a railroad. It is known also that the developed models have limitations and that the problem does not consider the treaty forming ability of trains at terminals or establishes conditions for scheduling the movement of wagons depending on the size of the trains. Constraints on the abilities of excerpts from the mesh and blocking issues for the wagons are not considered. Moreover, the proposed model does not address problems related to fleet traction material. In this sense, it is desirable to develop future works that complement the approach developed.

The results and the very low time spent for obtaining the solution show that by dividing the global problem of planning the allocation of freight wagons in a small enough problem and provided a structured approach feasible, facilitating the design of a simple modeling of easy to perform and can quickly reach the optimum. Moreover, the proposed allocation of wagons, in certain amounts, confers flexibility to the resolution process and the application of these models is not limited to the academic sphere and can be adopted in practice, as a tool of planning. 
Despite the limitations, the models are useful because they provide analysis and support to the planning done by offering the analyst the opportunity to learn in detail (on a tactical and operational level) all deficiencies analyzed for the railroad, as well as evaluating the proposition targets compliance retention times in destinations, commuting times, number of wagons retained for maintenance, the need for increased fleet and even the profitability or viability of the demands of the program of transport operating on the assumptions in force.

The models were developed from the observation of planning problems experienced by the wagons CFN - Northeastern Railway Company. Therefore, the methods and results presented here are derived from the experiment. However, it is believed that many of the approaches presented solution can be applied to planning problems allocating wagons perceived by Brazilian railroads.

\section{References}

Alfieri, A., Groot, R., Kroon, L., \& Schrijver, A. (2006). Efficient circulation of railway rolling stock. Transportation Science, 40(3), 378391. http://dx.doi.org/10.1287/trsc.1060.0155.

Alvarenga, A., \& Novaes, A. (2001). Logística aplicada: suprimento e distribuição física (3rd ed., p. 194). São Paulo: Edgard Blücher.

Ballou, R. (2006). Gerenciamento da cadeia de suprimentos: logística empresarial (5th ed., p. 616). Porto Alegre: Bookman.

Cordeau, J., Toth, P., \& Vigo, D. (1998). A survey of optimization models for train routing and scheduling. Transportation Science, 32(4), 380-404. http://dx.doi.org/10.1287/trsc.32.4.380.

Crainic, T., \& Hall, R. (2003). Long-haul freight transportation. In R. Hall (Ed.), Handbook of transportation science (2nd ed., pp. 451516). USA: Springer.

Dejax, P., \& Crainic, T. (1987). A review of empty flows and fleet management models in freight transportation. Transportation Science, 21(4), 227-248. http://dx.doi.org/10.1287/trsc.21.4.227.

Fukasawa, R. (2002). Resolução de problemas de logística ferroviária utilizando programação inteira (Master's thesis). Departamento de Engenharia Elétrica, Pontifícia Universidade Católica do Rio de Janeiro, Rio de Janeiro.

Haghani, A. (1989). Formulation and solution of a combined train routing and makeup, and empty car distribution model. Transportation Research Part B: Methodological, 23(6), 433-452. http://dx.doi.org/10.1016/0191-2615(89)90043-X.

Holmberg, K., Joborn, M., \& Lundgren, J. (1998). Improved empty freight car distribution. Transportation Science, 32(2), $163-173$. http://dx.doi.org/10.1287/trsc.32.2.163.

Joborn, M., Crainic, T., Gendreau, M., Holmberg, K., \& Lundgren, J. (2004). Economies of scale in empty freight car distribution in scheduled railways. Transportation Science, 38(2), 121-134. http://dx.doi.org/10.1287/trsc.1030.0061.

Powell, W., \& Carvalho, T. (1998a). Dynamic control of logistics queueing networks for large-scale fleet management. Transportation Science, 32(2), 90-109. http://dx.doi.org/10.1287/trsc.32.2.90.

Powell, W., \& Carvalho, T. (1998b). Real-time optimization of containers and flatcars for intermodal operations. Transportation Science, 32(2), 110-126. http://dx.doi.org/10.1287/trsc.32.2.110.

Sayarshad, H., \& Ghoseiri, K. (2009). A simulated annealing approach for the multi-periodic rail-car fleet sizing problem. Computers \& Operations Research, 36(6), 1789-1799. http://dx.doi.org/10.1016/j.cor.2008.05.004.

Received: July 12, 2015

Accepted: Feb. 9, 2017 